\title{
Heritage Language and Ethnic Identity: A Case Study of Korean-American College Students
}

\author{
Clara Lee Brown \\ The University of Tennessee, Knoxville \\ U. S. A.
}

The current study explores how heritage language proficiency affects the ethnic identity of four Korean-American college students who have maintained a high level of heritage language proficiency. Findings from in-depth interviews are consistent with previous studies which show close relationships between heritage languages and ethnic identity, yet the study reveals that a high level of heritage language proficiency is not necessarily associated with a heightened sense of ethnic identity for the selected students. Interview data suggest that participants' perceived expectations from society in general contribute to identity conflicts. A path to maintaining heritage language should start from creating a safe environment, especially in schools where heritage language speakers are protected from negative stereotypes.

\author{
Review of the Literature \\ Methodology \\ Findings \\ Discussion \\ Endnote \\ References \\ Appendix
}

Heritage language is a complex issue that affects immigrant youths who live in bilingual worlds. They may look different, speak a different language, practice different religions, and follow different cultural rituals from the larger American society. What is it like to be who they are? How does being different influence their sense of identity? With an increase of the immigrant population in the United States, it is important to pay attention to the psychological and emotional well-being of students whose language and culture are different from those of the monolingual English-speaking population. To that end, one of the emerging areas of concern in the educational community is bilingual youths' identity, specifically their ethnic identity, since language and identity are intricately related to each other (Cho, 2000; Phinney, Romero, Nava, \& Huang, 2001; Tse, 2000).

It has been argued that the linguistic situation of bilingual students is more complex than that of monolingual English-speaking students who do not have to deal with language issues within the context of heritage (Lee, 2002; Quintana, 2007). As the multi-ethnic population grows faster than that of the monolingual English-speaking Whites (U.S. Census Bureau, 2002), it is important to better understand how bilingual youths perceive themselves and come to terms with their identity while living in a society that dichotomizes majority versus minority and English-speakers versus non-English speakers. Do they resolve conflicting 
identities resulting from living in two different cultures in order to achieve bilingual and bicultural identity? Or do they identify themselves with one culture over the other?

This study attempted to shed some light on the intimate interplay between heritage language and ethnic identity, by exploring the multifaceted nature of ethnic identity held by young Korean adults who maintained their heritage language. The study examined the factors that contribute to their sense of who they are, either positively or negatively, and the role heritage language plays in ethnic identity. The study also looked into the ways in which conflicts contribute to forming ethnic identity, in particular, how these youths resolve the conflict between who they think they should be and who they want to be.

\section{Review of the Literature}

\section{Construction of Identity}

Identity is multifaceted and complex, as one's identity is based on myriad factors such as religious orientation, culture, education, community influences, family values, and belief systems (Myhill, 2003). This sense of identity causes individuals to behave in certain ways. According to Tajel and Turner's (1986) Social Identity Theory, people first categorize themselves into groups, then identify themselves within a certain group. That is, when considering identity, individuals consider it from both social and personal perspectives. Social and personal identities are two distinguishable entities, yet they cannot be regarded as separate because one cannot be isolated from a social milieu where interaction with others is inevitable.

Phinney (1990), who expanded Tajfel and Turner's concept of identity to ethnic identity formation, defines ethnic identity as "a dynamic, multidimensional construct that refers to one's identity, or sense of self as a member of an ethnic group" (p. 63). Phinney (2003) also adds that, for immigrant youths, it is their social identity that becomes ethnic identity because they categorize themselves based on their ethnic group membership. For minorities, social identity has more impact on individual identity in which more layers exist based on how they perceive themselves as well as how they are perceived by others.

The social influence on identity, however, does not seem to be uniformly applied to all ethnic groups. Feuerverger (1991) reported, from a study conducted on groups of Italian, Portuguese, Chinese, Korean, Japanese, and Hebrew students in a university in Canada, that Jewish students demonstrated the highest level of ethnic identity among the participants while Japanese students showed the lowest. It appears that there is no clear explanation regarding the different degrees of ethnic identity held by various ethnic groups. 
Individual identity, as opposed to group identity, is thought to form in a linear and predictable manner as one develops psychological and chronological maturity as shown in Piaget's or Erikson's psychological development theories (Erikson, 1963; Flavell, Miller, \& Miller, 2002). The core thesis of Piaget or Erikson is that individuals typically go through discrete stages of development, and each stage can be marked with sound development or lack thereof resulting in psychological problems.

Tse $(1997 ; 1998 ; 2000 ; 2001)$, who situated individual identity formation in the framework of ethnic identity development, argues that visible ethnic minorities who are identified by their non-White features neither necessarily go through all prescribed stages of the model in a linear fashion nor reach the highest level of the ethnic identity formation stage. Some favor the dominant culture and do not necessarily develop ethnic identity. This might have to do with the individual's ambivalent feelings toward the ethnic culture. Others develop personal identity by incorporating their ethnicity and the dominant culture's expectations.

\section{Ethnic Identity and Heritage Language}

Many studies have identified a positive relationship between one's ethnic identity and the degree of heritage language fluency (Phinney, Romero, Nava, \& Huang, 2001; Tse, 1997). Cho (2000) studied 1.5- and second-generation Korean Americans and found that participants with greater heritage language competence showed a stronger sense of who they are. Along the same vein, Soto (2002) concluded that bilingual Puerto Rican children who had high levels of competence in Spanish demonstrated a strong sense of ethnic identity as Puerto Rican.

Other research that investigated the impact of weekend heritage language schools on ethnic identity is highly informative and sheds light on close links between the two factors. Japanese American students (Chinen \& Tucker, 2006; Shibata, 2000) and Japanese Canadians (Oketani, 1997) demonstrated a stronger sense of ethnic identity after attending Japanese Saturday school. Another study (Wright \& Taylor, 1995) conducted on Inuit children in Canada reported that the self-esteem of these children significantly increased after they enrolled in a heritage language program teaching Inuktitut. The findings from You's (2005) study of young Korean children enrolled in Korean weekend school were also consistent with those of the studies mentioned previously. The hypothesis that individuals with greater heritage language proficiency have a stronger ethnic identity or show a more positive attitude toward their ethnic group is well supported and documented as shown above.

Nonetheless there are some conflicting findings regarding the relationship between heritage language proficiency and ethnic identity. Mah (2005), who surveyed second generation Chinese adults, found that heritage language is only linked to participants' ability to participate in cultural rituals such as ethnic 
activities, but not to ethnic pride or core values of Chinese groups. Similar results were reported in Smolicz's (1992) study conducted in Australia. While Polish Australians held on to the idea that heritage language is a core value to their community as a group, Welsh and Chinese Australians did not believe that maintaining their heritage language was important to their ethnicity.

While recognizing that identity is complex, compound, and even contradictory, it may be concluded that the ability to speak the heritage language can help ethnic minorities develop a better sense of who they are as ethnic individuals in general. It is also highly likely that those with high levels of heritage language competence make meaningful connections to their own group of people. What is not certain is whether heritage language proficiency is sufficient enough to provide a path to ensuring positive ethnic identity formation for youths of all ethnic backgrounds.

\section{Identity Conflict}

In forming identity, there can be confusion or conflict for those who do not successfully establish a positive identity. The concept of conflict in identity development was elaborated by Erikson (1963) who theorized that children and adolescents face the possibility of identity conflict in each developmental stage if social conditions or social interactions are not conducive to developing a sound ego. Erikson postulates that it is crucial for children to be surrounded by a supportive social environment so that they can appropriately develop a positive sense of who they are. A supportive social environment is even more important for bilingual/bicultural children than for monolingual and monocultural children in developing identity. Brown (2003) emphasizes the importance of monitoring bilingual children's identity formation since they are faced with negotiating differences in personal values and expectations from two different cultures. Tse (1998) also explains that ethnic minorities tend to believe that the majority group holds more prestige and status; thus, they feel the need to adopt the majority culture and to conform to it. As a result, those who favor the dominant culture do not develop a strong ethnic identity. Noels and Clement (1996) explain that adolescents and adults who speak a low status language tend to identify themselves more with the majority language and culture while their identification with their heritage language and culture is decreased. These studies show that the desire for acceptance and belonging can often create confusion and alienation, especially for young bilingual adolescents.

Ethnic stereotypes can offset the ways in which ethnic individuals feel about themselves in that if they perceive that they are linked with ethnic stereotypes, their self-identity could suffer even if they have high selfesteem (Tajfel \& Turner, 1986). It seems that negatively portrayed collective identity dominates individuals' identity. Many studies (Farver, Xu, Bhadha, Narang, \& Liebar, 2007; Khan \& Lambert, 2001; Kim-ju \& Liem, 2003) show that ethnic minorities felt better about themselves when their ethnic group was 
positively reflected by the majority. Conversely, it would be easier for ethnic minorities to maintain a strong self-ethnic identity when their collective identity is viewed favorably by the majority. It is said that Asian Americans are more grouporiented than European Americans, who are more individualistic (Bracey, B'amaca, \& Uma na-Taylor, 2004). Implied is that the impact of negative stereotypes would weigh heavier on Asian minority youths.

\section{Methodology}

\section{Participants and Data Collection}

A case-study methodology was selected so that study participants could freely express what was on their mind, especially regarding issues that are personally sensitive to them (Hatch, 2002; Patton, 1990). The interview procedure employed a combination of structured and semistructured interviews. All participants were presented with the same basic set of essential questions in order to reveal similarities and differences among participants' thoughts regarding the study focus. At the same time, participants were allowed to elaborate their thoughts.

College-age students were purposely selected to participate in the study. College students are young adults who have progressed through several stages of self-identity formation and have a fairly strong sense of self compared to younger students. In order to recruit a pool of possible participants, Korean churches were contacted in the area where the study took place. Korean churches are known to play a role as community centers (Shin, 2002) where socializing can take place, in addition to being houses of worship. The selected participants from the church were attending a local university located in the southeast region of the U.S. The following stipulations guided participant selection for this study:

(1) Participants were either born in the U.S. or came to the U.S. before kindergarten;

(2) Both birth parents are Korean;

(3) All participants are able to speak Korean proficiently; however, their literacy level was not screened;

(4) All are undergraduate students;

Some studies (Lee \& Oxelson, 2006) have found significant gender differences in ethnic identity, while others have not (Dion \& Dion, 2004). To minimize the effect of gender on the results, an equal number of male and female participants were selected for the study. From a pool of 8 volunteers, the author, a native speaker of Korean, orally screened the participants for Korean proficiency. Each volunteer met with the author individually for 20 minutes. Based 
on the screening, a total of 4 (2 male and 2 female) participants who demonstrated native-like proficiency in Korean were selected. Table 1 below provides participants' demographic information. The names used are pseudonyms.

Table 1.Description of the Participants

\begin{tabular}{|c|c|c|c|c|}
\hline Name & Age & $\begin{array}{l}\text { Year } \\
\text { College }\end{array}$ & Birth Place & $\begin{array}{l}\text { Attended } \\
\text { Classes }\end{array}$ \\
\hline Eddie & 20 & Sophomore & U.S. & No \\
\hline George & 19 & Freshman & $\begin{array}{l}\text { Korea, moved when } 1.5 \\
\text { months old }\end{array}$ & Yes, very briefly \\
\hline Erin & 19 & Freshman & $\begin{array}{l}\text { Korea, moved when } 6 \\
\text { months old }\end{array}$ & Yes, until high school \\
\hline Ruby & 19 & Freshman & U.S. & Yes, until high school \\
\hline
\end{tabular}

The interview protocol was devised to elicit the participants' perceptions, thoughts, and experiences along two threads-one related to identity and the other to heritage language. The interviews consisted of open-ended questions prepared by the author (see Appendix A). Based on the first interview, follow-up questions were added on an individual basis for subsequent interviews. The following research questions were posed:

(1) In what way does heritage language proficiency influence young Korean adults in developing a sense of ethnic identity?

(2) What are the characteristics of ethnic identity of these young Korean adults who maintain Korean heritage language?

Data were collected through one-on-one interviews, which were conducted entirely in English. A digital voice recorder was used to record the interviews. With each interview lasting one to two hours maximum, each participant was interviewed a total of three times. At the completion of the third interview, the author felt that no follow-up questions were needed to address the research questions and concluded that the participants fully shared personal insights regarding the research focus. Prior to data collection, the author obtained human subjects approval, and all procedures and cautions specified by the university review board were closely followed.

\section{Data Analysis}

Recorded interviews were transcribed and collapsed into one Word document. Data analysis was conducted in several different phases. First, 
verbatim data in the word document were carefully examined to initially identify key words/phrases that participants might have used in answering interview questions. The identified key words for Research Question One included "speak Korean," "language," "heritage," "identity." For Research Question Two, the following key phrases were identified: "feel Korean," "feel American," "heritage language," and "ethnicity."

Second, the entire document was searched according to the key words/phrases identified in the first step. Using the "Find" function of the Microsoft Word program, it was determined whether the paragraphs contained the key words/phrases relevant to research questions. Once the identified text was considered to address the research questions, it was highlighted in color on the word document. During the second phase of the data analysis, key words/phrases such as "myself," "influence," and "I think/l believe" were further identified, another round of searching the document was conducted, and the texts were highlighted.

Third, in order not to overlook any verbatim data that might be related to research questions, an additional phase of analysis was conducted through QDA Miner, qualitative data analysis software package. QDA Miner was utilized to identify any hidden relationship between occurrences and co-occurrences of specific key words/phrases. Finally, for cross-analysis purposes, each interview question was examined across all four participants to identify any opposing views related to the identified themes.

\section{Findings}

Three broad themes were identified during data analysis. All three themes revealed how complex identity phenomena are for heritage language speakers. Findings reported here seemed to defy the commonly assumed positive relationship between heritage language and ethnic identity. The first identified theme was that dual identity is not necessarily a voluntary choice. Participants may call themselves Korean-American because they are aware of the fact that they were distinguished as such based on their physical appearances despite the fact that they might want to be seen as "American." The study also found that individuals with a high level of heritage language proficiency cannot be assumed to have a strong ethnic identity. Finally, the study findings revealed that negative stereotypes might be one of the sources of identity conflict for heritage language speakers.

\section{Ethnic Identity, Chosen or Given?}

Data analysis shows that, at least on the surface, all participants assumed dual identities of Korean and American, which Ghuman (1991) calls "hyphenated 
identity." The participants answered, when asked how they identify themselves, that they are Korean American, which sounds straightforward and simple. For example, one of the participants, George, said, "I'm American because I was born in America, but I'm Korean as well." Closer examination, however, revealed the complexity of forming ethnic identity for heritage language speakers. All participants said they were Korean because they are perceived as Korean and expected to be Korean by society at large based on the way they look. Erin's words illustrate the point:

I look Korean. Other people expect me to be Korean. If I don't know anything about being Korean, that would be ridiculous, being Korean is something that I have to do. Like, I look different on the outside, people can see me as a different person, so if I don't know my heritage, what if one of those people comes and asks me, "Oh, what nationality are you?"

These young people do not appear to have the freedom to choose an identity other than Korean. In other words, they inevitably identified themselves as Korean because that is what is expected of them. While Erin was more willing to accept societal expectations, Ruby's words revealed a clear case of involuntary identity: "I am an American girl who is trapped in a Korean body. It's important to stay in touch with the Korean side, but I feel like I'm White. I only look Korean."

Erin, who seemed to have a highly mature sense of dual identity, poignantly stated, "Society can have an influence, but then in the end, it's up to you like what you want to become...." Erin concluded that ultimately it is the individual who determines his or her own identity. Some, however, may not be strong or resilient enough to resist the identity that society chooses for them, which leads to inner conflicts for those heritage language speakers who do not want to be identified as ethnic.

Everyone, regardless of ethnic backgrounds, faces identity conflicts while growing up (Erikson, 1963; Phinney, 1990). For heritage language speakers, however, the chance of experiencing an identity crisis is increased because they have to deal with multiple, sometimes conflicting identities. Eddie's comments support the notion that the public is a force to be reckoned with for these participants:

Yeah, for me I care about what people think of me a lot, and at the same time, I really don't care about what people think about me, I guess among Koreans. I really don't care about what people [other Koreans] think about me. Yeah, for some reason. I really don't care what they [other Koreans] think about me but I do [sic] among Whites.

Brown (2003) argues that heritage language speakers with ethnic backgrounds have a "public identity" that can be different from their "private identity" (p. 61). When Asian heritage language speakers, in particular, who privately think of themselves as American, are confronted with their identity in public, they feel obligated to take on their Korean ethnicity because this is the expectation of the public. Physical markers of ethnicity seem to play a large role 
for Asians. Based solely on their facial features, they seem to have no other choice but accepting a Korean identity.

\section{Influences of Heritage Language on Ethnic Identity}

A close relationship between one's ethnic identity and heritage language concurs with the findings in the literature: the stronger the heritage language proficiency, the more positive the sense of ethnic identity. Participants in this study indicated that their being able to speak Korean contributed to making them feel positive about being Korean. Erin said that her ability to speak Korean helped her find a Korean identity and that without her ability to speak the heritage language she would feel American, not Korean:

I couldn't really say that I am Korean unless I knew how to speak it. Speaking Korean helps me keep in touch with my roots. And being able to speak Korean makes me feel more like a Korean person. Being able to speak Korean shaped my identity, and Korean is just my identity. Yeah, I think language deals with a lot of it because if I can't speak Korean, I don't know if I would really feel Korean, because language is a big part, I think. Like, I have to be able to communicate with other Koreans, and I have to be able to like, to read Korean and know what they're talking about, because if I didn't, l'd just feel like I was completely Americanized.

Eddie made a strong statement about how his fluency in Korean helped him learn more about himself. He seemed quite sure about who he really is:

My Korean helped me know more about myself. When I have deep conversations in Korean, I get this feeling like I get to know more about myself and I get to be more in touch with myself than other Koreans who don't speak Korean.

These participants who developed high level of competence in their heritage language seemed secure in their identity in general and had better defined selfconcepts of who they are in the world where two different languages and cultures can clash and conflict.

Nevertheless, heritage language proficiency does not seem to guarantee a positive ethnic identity. Ruby, who spoke Korean fluently, did not show a positive ethnic identity. She asserted that she did not feel Korean when she spoke Korean. At one point, she said, "I'm good at language. I think that is why I'm good at Korean. I'm also good at Spanish." To her, Korean is just another language in which she is proficient. She did not attach any emotion to her heritage language, while the other participants did. She also did not differentiate between her heritage language, Korean, and her fluent foreign language, Spanish. She also added that, "I don't feel any different when I speak Korean from when I speak Spanish with my Spanish class teacher." As shown in the excerpt below, Ruby explicitly dissociated herself from being Korean, as well as being identified as Korean: 
I'm basically an American girl trapped in a Korean body... I'm not like any other Korean. I don't dress like Korean girls, I don't like kimchi ${ }^{1}$, I don't play piano, or I don't listen to my parents like other typical Korean girls do. I listen to American music and American TV programs. I feel more comfortable with White people.

Ruby's strong words not only illustrate the multiplicity of ethnic identity, but also reveal the fact that strong heritage language proficiency is not a sufficient condition for ethnic minorities to feel positive about their identity. The following excerpt offers an explanation as to why she does not feel Korean or want to feel Korean:

My brother, his best friend and I were talking about this, how Korean a-jusi [referring to older adult males] are like. Whenever they go out, they always wear like a polo shirt, plaid pants, and like those little penny loafers and like socks pulled right up to here and it's just embarrassing. Cause [when] you see other American a-ju-si, they look normal wearing nice slacks and a shirt. Here they are wearing like plaid shorts and a polo shirt and like socks pulled up all the way up to their knees. The other day, my brother and I were just laughing about that. Cause we saw my dad do it, and we were actually laughing about it. We were like, we can't wait until we start dressing like that.

The apparent lack of emotional connections to feeling Korean may have to do with the negative perceptions she held based on her own observations of Koreans, in this case how Korean older males dress. As shown in the excerpt above, Ruby was highly critical of the way older Korean males dress, actually ridiculing them for it. It seems that the source of her detachment from feeling Korean stemmed from her rejection of Korean culture as she saw it. Ruby's other previous excerpt supports this interpretation-“' don't dress like Korean girls. I don't play piano or I don't listen to my parents like other typical Korean girls do." Ruby apparently assumed that one of the characteristics of Korean culture is that it makes people behave in a certain way. Her words indicate that she abhors Koreans' cultural practice of conformity. Ruby's case clearly illustrates that high heritage language proficiency does not necessarily mean strong ethnic identity: some can speak the heritage language fluently, yet these individuals do not form a positive sense of ethnic identity if they reject their own culture.

\section{Characteristics of Ethnic Identity: Being Proud, Yet Embarrassed}

The participants who displayed a strong sense of Korean identity and pride also reported how embarrassed they are in public places. The cause of embarrassment seems to be the negative stereotypes attached to Asians and minorities in general. Eddie provided some interesting comments exemplifying how proud he is to be Korean, yet how he is embarrassed at the same time. 
These sentiments were expressed quite strongly several times throughout the interview:

The other day at the gym, these Chinese girls were talking so loud. I was like 'Oh, I gotta go.' I hurried my exercise routine and left because I was afraid that other people might associate me with them, you know. I don't know, I don't know why, they weren't mean or anything, I just felt embarrassed. I didn't want people to think we are all like that.

Also, according to Eddie, he had no problem 'hanging out' with White friends and being the only Korean, but if White friends saw him with other Koreans, he would be embarrassed:

Yeah, when I'm kind of hanging out with a lot of Korean people where there are a lot of White people, like, if I go to a mall or a movie, I'm kind of embarrassed. And when I'm the only Korean with a lot of White people, I feel comfortable. I don't know why.

This contradictory attitude toward one's ethnic identity indicates a struggle between "Proud to be Korean" and "Don't want to be seen as Korean." When bilingual individuals say that they are proud to be Korean (or Mexican), they may intend to be sincere and genuine. They may add, "I don't care what you think of me. I am proud of my heritage." Their expressed pride in being a member of a minority group, however, does not mean they are immune to such negative stereotypes. It has been argued that collective identity weighs more than personal identity in terms of forming ethnic identity (Phinney, 1990; Tajfel \& Turner, 1986). The concern is that heritage language speakers with a seemingly strong sense of ethnic identity struggle with the identity conflicts caused by negative stereotypes. This is potentially harmful for their identity formation and might lead them to self-rejection and even embarrassment. It could be said that these young heritage language speakers are, at a deeper level, trapped in identity conflicts as long as society associates people of ethnic backgrounds with negative stereotypes. One cannot merely say to these youths, "Be Korean and be proud." It is not as simple as it sounds.

\section{Discussion}

In ensuring the sound development of ethnic identity, one option for ethnic minorities is to adopt a dual or hyphenated identity, for these participants, Korean American. Is a dual identity chosen by heritage language speakers or is it imposed on them? One of the findings of this study is that developing one's ethnic identity is not solely the individuals' own decision. The participants assert that they are American and that is how they identify themselves. At the same time, they are aware of the fact that the public inevitably imposes an ethnic identity on them. Brown (2003) explains this dual identity as "public identity" vs. "private identity." 
It is through accepting a public identity based on physical features that some heritage language speakers embrace the cultural part of their ethnic identity: i.e., the culture or customs that comes with it. If heritage language speakers fully embrace the public notion of ethnic identity, in addition to the private desire to be identified as American, they attain dual identity. The heritage language speakers in this study who appreciated their Korean heritage as well as their American identity are considered to have achieved dual identity.

Nonetheless other heritage language speakers accept only the appearance aspect of their public identity and reject the cultural aspect. A sharp discrepancy then forms between the way they feel about who they are and the way society identifies them, as shown in Ruby's case. Recall that Ruby made fun of the way older Korean males dress, and she even seemed proud of the fact that she did not behave as stereotypical Korean girls do. She does not appreciate Korean culture and rejects the Korean side of her identity. Ruby only acknowledges herself as Korean as far as facial features are concerned. In her mind, she is unequivocally American.

Confusion and conflict can ensue even if the heritage language is highly developed. Conventional wisdom maintains that that ethnic identity is entirely up to the individual, but this study shows that ethnic identity is a multifaceted, complex matter that goes beyond merely linking heritage language proficiency with ethnic identity and that heritage language fluency is not a sufficient condition for developing ethnic identity. In forming a positive and healthy ethnic identity, embracing the heritage culture appears to be more important than maintaining the heritage language. If ethnic minority students are more appreciative of their culture, they are more likely to cultivate a strong ethnic identity, as opposed to those who merely maintained the heritage language without an appreciation of the heritage culture.

Negative stereotyping is found to be a greatly influencing factor for the participants with respect to the way they feel about their ethnicity (Khan \& Lambert, 2001). How ethnic minority students feel about themselves should not be entirely considered as a personal matter. This study has shown that society exercises a great influence on these individuals, negatively impacting the way ethnic minority students feel about their ethnicity. Therefore, the public needs to share some level of responsibility as to the way heritage language speakers feel. If the great majority of the public accepted ethnic diversity and practiced tolerance, heritage language speakers would not feel different about themselves. They might feel that they are as much American as anybody else without rationalizing who they should be, and they would not have to be made aware of how they are perceived as "outsiders" by the general public.

One way to make the public more supportive of ethnic diversity is through education. Schools must strive for multicultural education where heritage language speakers' culture, language, and experiences are affirmed and validated. Schools should be places where heritage language speakers feel safe to assert who they are and to feel proud of their heritage (Dutro, Kazemi, Balf, \& 
Lin, 2008). Embracing the heritage culture for them would then not be a difficult choice and might lead them to heritage language maintenance.

In closing, a discussion of study limitations is in order. The number of participants in this study is relatively small and findings from the study, while interesting, should be interpreted with caution in the different heritage language context. Further studies with a larger number of participants are recommended.

\section{Endnote}

1. Kimchi is a cabbage dish seasoned with hot pepper, garlic and ginger. It is a staple food in the Korean diet and is considered Korea's national dish. In Korean folk culture, Kimchi is often associated with Korean identity.

\section{References}

Brown, C. L. (2003). The making of a bilingual/bicultural identity: A case study of a Japanese-American child. Japan Journal of Multilingualism and Multiculturalism, 9(1), 52-68.

Bracey, J. R., B’amaca, M. Y., \& Uma na-Taylor, A. J. (2004). Examining ethnic identity and self-esteem among biracial and monoracial adolescents. Journal of Youth and Adolescence, 33(2), 123-132.

Chinen, K., \& Tucker, G. R. (2006). Heritage language development: Understanding the roles of ethnic identity, schooling and community. In K. Kondo-Brown (Ed.), Heritage language development: Focus on East Asian immigrants (pp. 89-126). Philadelphia: John Benjamins Publishing Company.

Cho, G. (2000). The role of heritage language in social interactions and relationships: Reflections from a language minority group. Bilingual Research Journal, 24(4), 369-384.

Dion, K. K., \& Dion, K. L. (2004). Gender, immigration generation, and ethnocultural identity. Sex Roles, 50(5/6), 347-355.

Dutro, E., Kazemi, E., Balf, R., \& Lin, Y.-S. (2008). "What are you and where are you from?" Race, identity, and the vicissitudes of cultural relevance. Urban Education, 43(3), 269-300.

Erikson, E. H. (1963). Childhood and society. New York: W. W. Norton \& Company.

Farver, J., Xu, Y., Bhadha, B., Narang, S., \& Liebar, E. (2007). Ethnic identity, acculturation, parenting beliefs, and adolescent adjustment. Merrill-Palmer Quarterly, 53(2), 184-215. 
Feuerverger, G. (1991). University students' perceptions of heritage language learning and ethnic identity maintenance. Canadian Modern Language Review, 47(4), 660-677.

Flavell, J. H., Miller, P. H., \& Miller, S. A. (2002). Cognitive development ( $4^{\text {th }}$ ed.). Upper Saddle River, NJ: Prentice Hall.

Ghuman, P. S. (1991). Best or worst of two worlds? A study of Asian Adolescents. Educational Research, 33(2), 121-132.

Hatch, J. A. (2002). Doing qualitative research in education settings. Albany, NY: State University of New York Press.

Khan, S. R., \& Lambert, A. J. (2001). Perceptions of "rational discrimination": When do people attempt to justify race-based prejudice? Basic and Applied Social Psychology, 23(43-53).

Kim-ju, G. M., \& Liem, R. (2003). Ethnic self-awareness as a function of ethnic group status, group composition, and ethnic identity orientation. Cultural Diversity and Ethnic Minority Psychology, 9(3), 289-302.

Lee, J. S. (2002). The Korean language in America: The role of cultural identity in heritage language learning. Language, Culture and Curriculum, 15(2), 117-133.

Lee, J. S., \& Oxelson, E. (2006). "It's not my job": K-12 teacher attitudes toward students' heritage language maintenance. Bilingual Research Journal, 30(2), 453-477.

Mah, B. (2005). Ethnic identity and heritage language ability in second generation Canadians in Toronto. Unpublished master's thesis, Ryerson University, Toronto, Canada.

Myhill, J. (2003). The native speaker, identity, and the authenticity hierarchy. Language Sciences, 25(1), 77-57.

Noels, K. A., \& Clement, R. (1996). Communicating across cultures: Social determinants and acculturative consequences. Canadian Journal of Behavioral Science, 28(3), 214-228.

Oketani, H. (1997). Additive bilinguals: The case of post-war second generation Japanese Canadian youths. Bilingual Research Journal, 21(4), 359-379.

Patton, M. Q. (1990). Qualitative research and evaluation methods. Newbury Park, CA: Sage.

Phinney, J. S. (1990). Ethnic identity in adolescents and adults: Review of research. Psychological Bulletin, 108(3), 499-514.

Phinney, J. S. (2003). Ethnic identity and acculturation. In K. M. Chun, P. B. Organista \& G. Marin (Eds.), Acculturation: Advances in theory, measurement, and applied research (pp. 63-82). Washington, DC: American Psychological Association. 
Phinney, J. S., Romero, I., Nava, M., \& Huang, D. (2001). The role of language, parents, and peers in ethnic identity among adolescents in immigrant families. Journal of Youth and Adolescence, 30(2), 135-153.

Quintana, S., M. (2007). Racial and ethnic identity: Developmental perspectives and research. Journal of Counseling Psychology, 54(3), 259-270.

Shibata, S. (2000). Opening a Japanese Saturday school in a small town in the United States: Community collaboration to teach Japanese as a heritage language. Bilingual Research Journal, 24(4), 465-474.

Shin, S. (2002). Differentiating language contact phenomena: Evidence from Korean-English bilingualism. Applied Psycholinguistics, 23(3), 337-360.

Smolicz, J. J. (1992). Minority languages as core values of ethnic cultures: A study of maintenance and erosion of Polish, Welsh, and Chinese languages in Australia. In K. J. S. K. W. Fase (Ed.), Maintenance and loss of minority languages (pp. 277-305). Philadelphia: John Benjamins Publishing Company.

Soto, L. D. (2002). Young bilingual children's perceptions of bilingualism and biliteracy: Altruistic possibilities. Bilingual Research Journal, 26(3), 599610.

Tajfel, H., \& Turner, J. (1986). The social identity theory of intergroup behavior. In S. Worchel, and Austin, W. (Ed.), Psychology of Intergroup Relations (pp. 7-24). Chicago: Nelson-Hall.

Tse, L. (1997). Affecting affect: The impact of ethnic language programs on student attitudes. The Canadian Modern Language Review, 53(4), 705728.

Tse, L. (1998). Seeing themselves through borrowed eyes: Asian Americans in ethnic ambivalence/evasion. MultiCultural Review, 7(2), 28-34.

Tse, L. (2000). The effects of ethnic identity formation on bilingual maintenance and development: An analysis of Asian American narratives. International Journal of Bilingualism Education and Bilingualism, 3(3), 185-200.

Tse, L. (2001). Resisting and reversing language shift: Heritage language resilience among U.S. native biliterates. Harvard Educational Review, 71(4), 676-708.

U.S. Census Bureau. (2002). Report: The foreign born population in the United States. Retrieved May 10, 2005, from http://www.census.gov/population/pop-profile/1999/chap17.pdf

Wright, S. C., \& Taylor, D. M. (1995). Identity and the language of the classroom: Investigating the impact of heritage versus second language instruction on personal and collective self-esteem. Journal of Educational Psychology, 87(2), 241-252.

You, B.-k. (2005). Children negotiating Korean American ethnic identity through their heritage language. Bilingual Research Journal, 29(3), 711-722. 


\section{Appendix}

Identity-Related Questions:

1. How would you identify yourself?

- What do you base your identity on?

2. What does it mean to be Korean?

3. What does it mean to become American?

4. Who decides your identity?

5 . Is being Korean a burden in any way?

6. Is there such a thing as being perfectly balanced between a Korean and American identity?

Heritage Language-Related Questions:

1. Has your being able to speak Korean shaped your ethnic identity in any way?

- Do you feel more Korean when you speak Korean?

2. What would you say the relationship between heritage language and identity is?

3. What would you say the relationship between language and culture is? 